\title{
Noninvasive Quantification of Fluid Mechanical Energy Losses in the Total Cavopulmonary Connection with Magnetic Resonance Phase Velocity Mapping
}

Anand K. Venkatachari

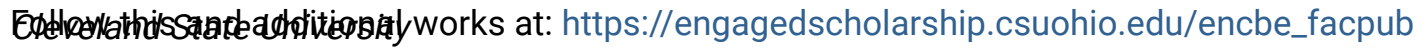

sarlart gf thellibiourtoping and Biomedical Optics Commons

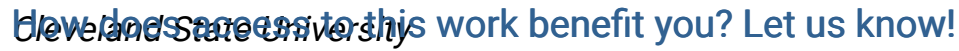

Publisher's Statement

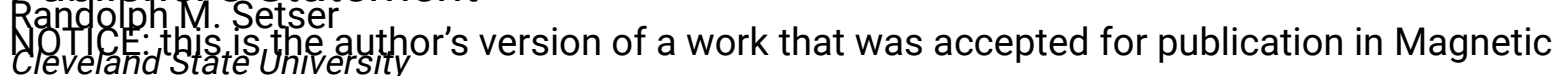

Resonance Imaging. Changes resulting from the publishing process, such as peer review,

Riffthagd, Bortlekitions, structural formatting, and other quality control mechanisms may not be reflectand Clipic Foundation. Changes may have been made to this work since it was submitted

toequglieatipatzAndafioitiolis version was subsequently published in Magnetic Resonance

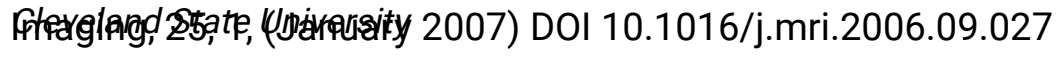

\section{Original Citation}

Venkatachari AK, Halliburton SS, Setser RM, White RD, Chatzimavroudis GP. Noninvasive quantification of fluid mechanical energy losses in the total cavopulmonary connection with magnetic resonance phase velocity mapping. Magn Reson Imaging. 2007;25:101-109.

\section{Repository Citation}

Venkatachari, Anand K.; Halliburton, Sandra S.; Setser, Randolph M.; White, Richard D.; and Chatzimavroudis, George P., "Noninvasive Quantification of Fluid Mechanical Energy Losses in the Total Cavopulmonary Connection with Magnetic Resonance Phase Velocity Mapping" (2007). Chemical \& Biomedical Engineering Faculty Publications. 111.

https://engagedscholarship.csuohio.edu/encbe_facpub/111

This Article is brought to you for free and open access by the Chemical \& Biomedical Engineering Department at EngagedScholarship@CSU. It has been accepted for inclusion in Chemical \& Biomedical Engineering Faculty Publications by an authorized administrator of EngagedScholarship@CSU. For more information, please contact library.es@csuohio.edu. 


\title{
Noninvasive quantification of fluid mechanical energy losses in the total cavopulmonary connection with magnetic resonance phase velocity mapping
}

\author{
Anand K. Venkatachari ${ }^{\mathrm{a}}$, Sandra S. Halliburton ${ }^{\mathrm{a}, \mathrm{b}}$, Randolph M. Setser ${ }^{\mathrm{a}, \mathrm{b}}$, \\ Richard D. White ${ }^{\mathrm{b}}$, George P. Chatzimavroudis ${ }^{\mathrm{a}, \mathrm{b}, *}$ \\ "Laboratory of Biofluid Mechanics and Cardiovascular Imaging, Department of Chemical and Biomedical Engineering. \\ Cleveland State University, Cleveland, $\mathrm{OH} 44115-2425$, USA \\ ${ }^{b}$ Section of Cardiovascular Imaging, Division of Radiology, The Cleveland Clinic Foundation, Cleveland, OH, USA
}

\section{Introduction}

The total cavopulmonary connection (TCPC) [1] is the most preferred surgical procedure to treat children with congenital heart disease that involves single-ventricle physiology. It is a (multistage) surgical connection of the superior and inferior vena cava (SVC and IVC, respectively) with the left and right pulmonary arteries (LPA and RPA, respectively) bypassing the right side of the heart. The superiority of

* Corresponding author. Department of Chemical and Biomedical Engineering, Cleveland State University, Cleveland, $\mathrm{OH} 44115-2425$, USA. Tel.: +1 216687 5396; fax: +1 2166879220 .

E-mail address: g.chatzimavroudis@csuohio.edu (G.P. Chatzimavroudis).

0730-725X/\$ - see front matter C 2007 Elsevier Inc. All rights reserved. doi:10.1016/j.mri.2006.09.027
TCPC over previous connections [2-4] is partially due to the more streamlined flow patterns in TCPC, less flow disturbances and, thus, lower blood flow energy losses. Conserving as much as possible the mechanical energy of blood that flows through the connection is of crucial importance, considering that the single ventricle is responsible for both the systemic and the pulmonary circulation. As a result, the fluid mechanical optimization of the TCPC has been investigated through several in vitro, numerical and in vivo studies [5-18], leading to improvements in the connection between the caval and pulmonary vessels.

To evaluate the fluid mechanical performance of TCPC, most previous experimental and numerical studies either addressed the flow patterns qualitatively via flow visualization or quantitatively by determining the mechanical 


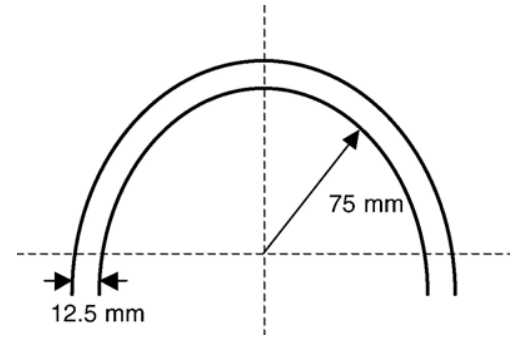

Fig. 1. The U-shaped tube model. The model was made of flexible tygon tubing; it was mounted in a polycarbonate vessel and connected to a steady flow loop.

energy losses from the mechanical energy balance equation. Although easily implemented experimentally, the mechanical energy balance approach is clinically impractical because it requires precise invasive pressure measurements in all four vessels (SVC, IVC, RPA and LPA) in infants and children. It is also of questionable reliability because of uncertainties in catheter localization and possible catheter movement in the flow field. Therefore, there is a need for a reliable, completely noninvasive approach to provide the energy dissipation in the TCPC.

Based on fluid mechanics theory [19], the fluid mechanical energy loss in the TCPC should be due to viscous dissipation (VD). This theory was validated by recent computational fluid dynamics (CFD) studies [20,21] that showed a close agreement between the calculated VD and the mechanical energy balance results of energy loss. In contrast to the mechanical energy balance approach, the calculation of the VD does not require any pressure data; only the three spatial components of the fluid velocity vector are necessary. Magnetic resonance (MR) phase velocity mapping (PVM) [22] is currently the only established clinical technique to measure all three spatial components of the velocity vector in every volume element of an imaging slice, showing high in vitro and in vivo accuracy and precision [23-34]. The advantage of MR PVM to measure the three-directional blood velocity has enabled the generation of velocity vector maps in vitro and in vivo, showing (qualitatively) the fluid mechanical superiority of the TCPC over other connections and the importance of the presence of caval offset and flaring at the connection site $[14,15,33-36]$.

The presence of the VD method combined with the availability of MR PVM offer a great potential for the development of a noninvasive protocol to quantitatively determine the energy losses of the TCPC in patients without the need for invasive pressure measurements. Nevertheless, before successfully applying the VD method clinically using MR PVM, it is necessary to assess the feasibility of the approach in a realistic clinical setting. Therefore, the aim of this study was to determine the potential of MR PVM to quantify the VD with reliability. MR PVM experiments and CFD simulations were performed in two flow models, and the experimental VD results were compared with the computational VD results that were used as reference.

\section{Methods}

The study consisted of two parts. In the first part, a simple U-shaped tygon tube was used to examine the feasibility of the VD method in a simple flow model free of the flow disturbances seen in TCPC. In the second part, a glass TCPC model was used to investigate the potential of the VD method in a physiologically more relevant flow environment.

\subsection{U-shaped tube studies}

Experimental and CFD studies were performed with a U-shaped tygon tube with an inside diameter of $12.5 \mathrm{~mm}$ and a radius of curvature of the bend equal to $75 \mathrm{~mm}$ (Fig. 1). To perform the experimental MR studies, the tube was mounted inside a polycarbonate container that was filled with water covering the tube in order to ensure a strong MR signal. The test section was then connected to a steady flow loop and it was inserted inside the bore of a 1.5-T whole-body Magnetom Sonata MR scanner (Siemens Medical Solutions, Erlangen, Germany). Water was circulated in the flow loop under steady-state conditions adjusted via valves and monitored via a precalibrated rotameter (Dakota Instruments, Orangeburg, NY, USA). A phased-array receiver coil was used to cover the test section in order to improve the signal-to-noise ratio and, thus, image quality.

Initial gradient-echo scout images were acquired to determine the position of the tube. Then, two types of MR acquisitions were performed. The first type consisted of a series of contiguous transverse images perpendicular to the tube long axis along the straight part of the tube, and oblique images, perpendicular to the tube long axis along the bend, covering the entire tube in order to provide the magnitude images for the computational reconstruction of

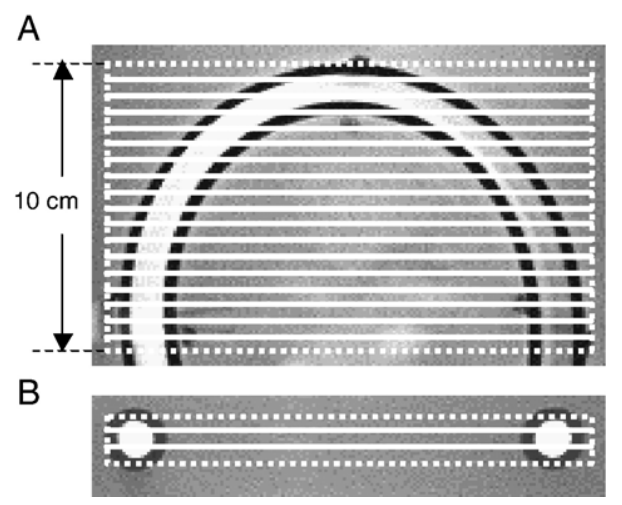

Fig. 2. Slice placement in the tube model for the MR PVM measurements. (A) Transverse slice orientation: 20 contiguous slices, $5 \mathrm{~mm}$ thick, were placed from the top of the bend to $10 \mathrm{~cm}$ away from it. (B) Coronal slice orientation: three contiguous slices, $5 \mathrm{~mm}$ thick, were placed covering the entire cross section of the tube. 
the geometry. The pulse sequence used was a gradient-echo with a slice thickness (ST) of $3 \mathrm{~mm}$, a field of view (FOV) of $256 \times 256 \mathrm{~mm}$ and a matrix size of $256 \times 256$ (thus resulting in an in-plane resolution of $1 \times 1 \mathrm{~mm}$ ).

The second type of MR acquisitions was performed to acquire the three-directional velocity data in order to experimentally apply the VD method and calculate the energy loss in the tube. The MR PVM image acquisition was performed by using a segmented $k$-space gradient-echo sequence, with three lines per segment, in two orientations, transverse and coronal (Fig. 2), in order to examine the effect of imaging slice orientation on the VD results. In the transverse orientation, a total of 20 contiguous images were acquired with a ST of $5 \mathrm{~mm}$ and a FOV of $192 \times 192 \mathrm{~mm}$. Three matrix sizes were used, $192 \times 192,256 \times 256$ and $320 \times 320$, resulting in an in-plane spatial resolution of $1 \times 1$, $0.8 \times 0.8$ and $0.6 \times 0.6 \mathrm{~mm}$, respectively. The effective repetition time (TR) was varied between 38 and $50 \mathrm{~ms}$ and the shortest echo time (TE) was used. The velocity encoding limit (Venc) was set to $60 \mathrm{~cm} / \mathrm{s}$. Similarly, in the coronal orientation, three contiguous images were acquired with a ST of $5 \mathrm{~mm}$ and a FOV of $256 \times 256 \mathrm{~mm}$. Three matrix sizes were used, $256 \times 256,320 \times 320$ and $448 \times 448$, resulting in an in-plane spatial resolution of $1 \times 1,0.8 \times 0.8$ and $0.6 \times 0.6$ mmrespectively. The effective TR was varied between 41 and $62 \mathrm{~ms}$ and the shortest TE was used. The Venc was again set to $60 \mathrm{~cm} / \mathrm{s}$. The MR PVM measurements were performed for two flow rates, 0.75 and $1.2 \mathrm{~L} / \mathrm{min}$. The corresponding Reynolds numbers were approximately 1250 and 2050, respectively, reflecting laminar flow.

The MR images that were acquired to construct the computational model were imported into a MATLAB code (The MathWorks, Natick, MA, USA) that recorded the spatial coordinates of the tube wall. These coordinates were then imported into the three-dimensional modeling software package Rhinoceros (Robert McNeel \& Associates, Seattle, WA, USA) as point clouds, so that all of the points associated with a particular curve were imported at the same time while maintaining their relationship to one

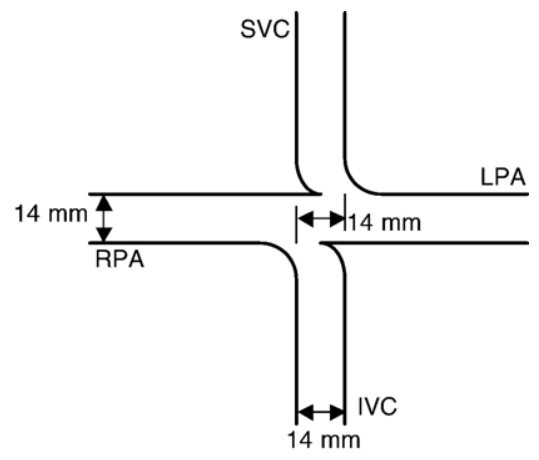

Fig. 3. The TCPC model. The model was made of glass, and the SVC and IVC were curved immediately before their connection to the LPA and RPA, respectively.

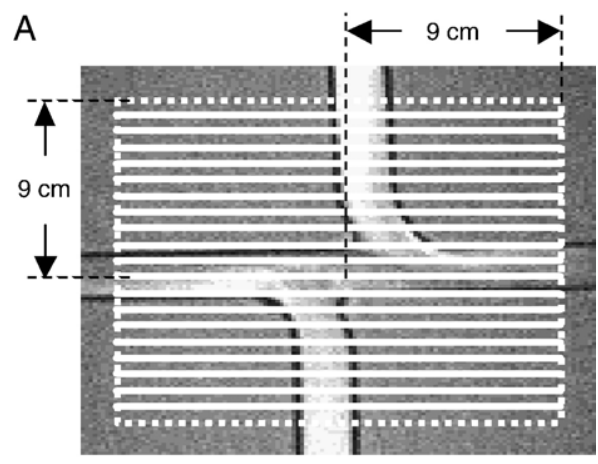

B

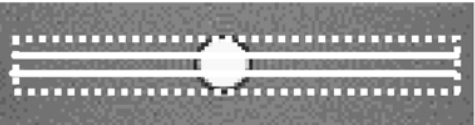

Fig. 4. Slice placement in the TCPC model for the MR PVM measurements. (A) Transverse slice orientation: 36 contiguous slices, $5 \mathrm{~mm}$ thick, were placed to cover a region from the center of the model to $9 \mathrm{~cm}$ away from it in both caval directions. (B) Coronal slice orientation: three contiguous slices, $5 \mathrm{~mm}$ thick, were placed covering the entire cross section of all vessels of the model.

another. A nonuniform, rational $\mathrm{B}$ spline was fit to the imported coordinates. Once all of the curves were created, they were smoothed to remove the roughness caused by partial volume effects. After smoothing, a surface was lofted over the curves. The use of both the transverse and the oblique images allowed the surface of the entire phantom to be created in a single step, as the curves provided the software with a logical lofting path to build the surface. The constructed model was then imported into Gambit (Fluent, Lebanon, NH, USA) and meshed by using hexahedral mesh elements. A series of meshed models was constructed with an increasing number of volume elements (cells), from 3000 to 274,000 . The CFD simulations were performed using Fluent (ver. 6.0, Fluent) for the same two flow rates used in the MR PVM experiments $(0.75$ and $1.2 \mathrm{~L} / \mathrm{min})$. Water ( $\rho=988 \mathrm{~kg} / \mathrm{m}^{3}, \mu=0.001 \mathrm{~kg} / \mathrm{m} \cdot \mathrm{s}$ ) was chosen as the fluid for the simulations. The experimentally measured inlet velocity profile with MR PVM was imported into Fluent as the inlet velocity boundary condition for the simulations. A zero gauge pressure was selected as the outlet boundary condition for all simulations.

\subsection{TCPC phantom studies}

Similar studies were performed with a TCPC phantom with curved connections between the SVC and the LPA and between the IVC and the RPA (Fig. 3). The inside diameter of the venae cavae and the pulmonary arteries was $14 \mathrm{~mm}$. There was an offset of one caval diameter between the points of connections of the cavae with the pulmonary arteries. Water was again used as the working fluid and its flow rate was adjusted via a series of valves with the help of three precalibrated rotameters (Dakota Instruments, Orangeburg, NY, USA). 
A
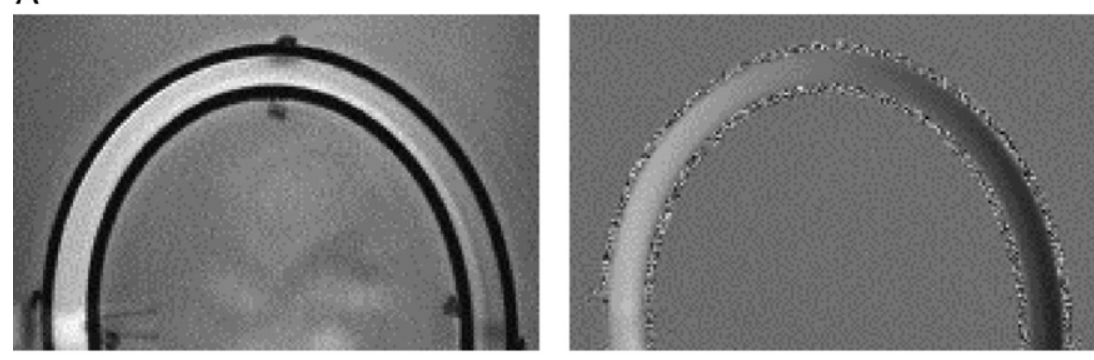

$\mathrm{B}$
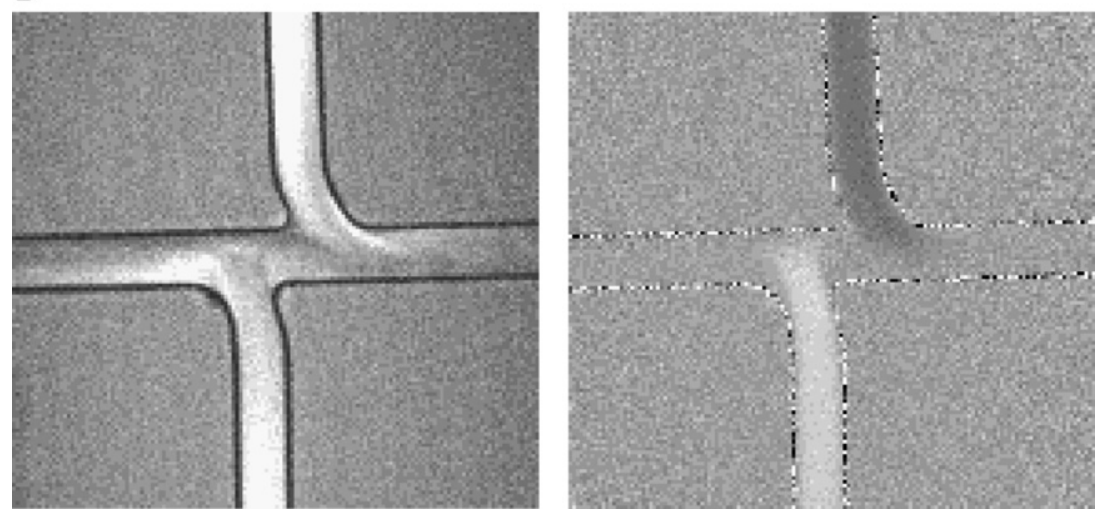

Fig. 5. (A) Magnitude (left) and phase (right) images of the tube model. (B) Magnitude (left) and phase (right) images of the TCPC model. In both models, the velocity in these particular phase images is encoded in the top-bottom direction. Two additional acquisitions were performed, encoding the left-right velocity component and the anterior-posterior velocity component.

A series of transverse gradient-echo images were acquired to construct the computational model for the CFD simulations in a similar manner to that described for the tube studies in the previous section. Then, segmented $k$-space (three lines per segment) MR PVM acquisitions were performed to acquire the three-directional velocity data for the VD method in two orientations, transverse and coronal (Fig. 4) in order to examine the effect of imaging slice orientation on the VD results. In the transverse orientation, a total of 36 contiguous images were acquired with a ST of $5 \mathrm{~mm}$ and a FOV of $256 \times 256 \mathrm{~mm}$. Three matrix sizes were used, $256 \times 256,320 \times 320$ and $448 \times 448$, resulting in an in-plane spatial resolution of $1 \times 1,0.8 \times 0.8$ and $0.6 \times 0.6 \mathrm{~mm}$, respectively. The effective TR was varied between 41 and $62 \mathrm{~ms}$ and the shortest TE was used. The Venc was set to $60 \mathrm{~cm} / \mathrm{s}$. In the coronal orientation, three contiguous slices with a ST of $5 \mathrm{~mm}$ and a FOV of $256 \times 256$ $\mathrm{mm}$ were enough to cover the entire model. Three matrix sizes were used, $256 \times 256,320 \times 320$ and $448 \times 448$, resulting again in an in-plane spatial resolution of $1 \times 1$, $0.8 \times 0.8$ and $0.6 \times 0.6 \mathrm{~mm}$, respectively. The effective TR was varied between 41 and $62 \mathrm{~ms}$ and the shortest TE was used. The Venc was again set to $60 \mathrm{~cm} / \mathrm{s}$. Flow entered the phantom through the SVC and IVC vessels and exited through the RPA and LPA vessels. Since water was used in the MR experiments, the flow rate was adjusted in order to achieve Reynolds numbers equal to those that would have been achieved with a fluid having a viscosity 3.5 times higher (to match the viscosity of blood) than that of water. The resulting total $\mathrm{SVC}+\mathrm{IVC}$ flow rate was $1.2 \mathrm{~L} / \mathrm{min}$ (corresponding to $4 \mathrm{~L} / \mathrm{min}$ for blood), equally divided between the two cavae. The RPA/LPA flow ratio was varied between 30:70 and 70:30 to simulate a range of resistance in the lungs. The corresponding Reynolds numbers in the cavae and pulmonary vessels were between approximately 540 and 1270 , reflecting the nature of laminar flow seen clinically in the TCPC.

The computational model of the TCPC phantom was constructed in the same manner as the computational tube model, based on the transverse images, using Gambit. A

A

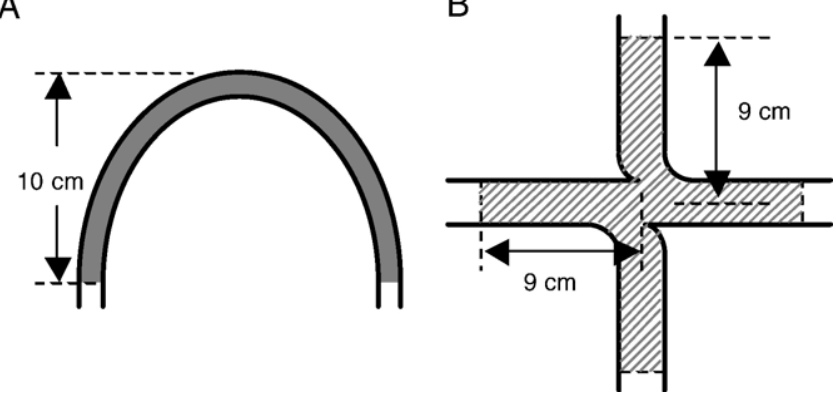

Fig. 6. Selection of the control volume (shaded areas) to perform the calculation of the VD from both the measured (with MR PVM) and the computed (with CFD) velocity data using Eq. (1) and Eq. (2). (A) Tube model, (B) TCPC model. 
A

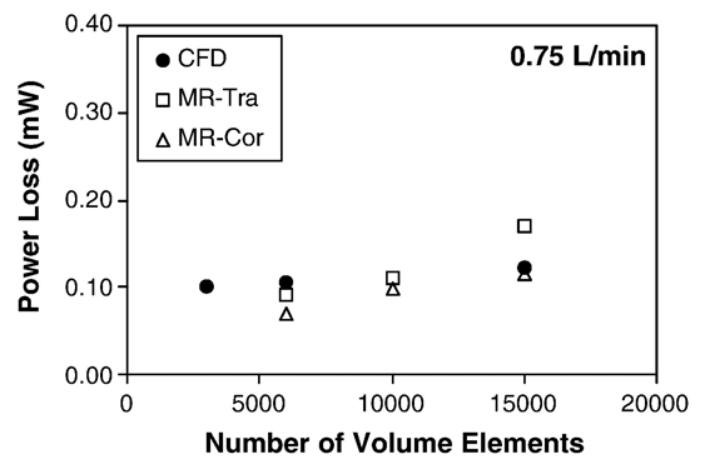

B

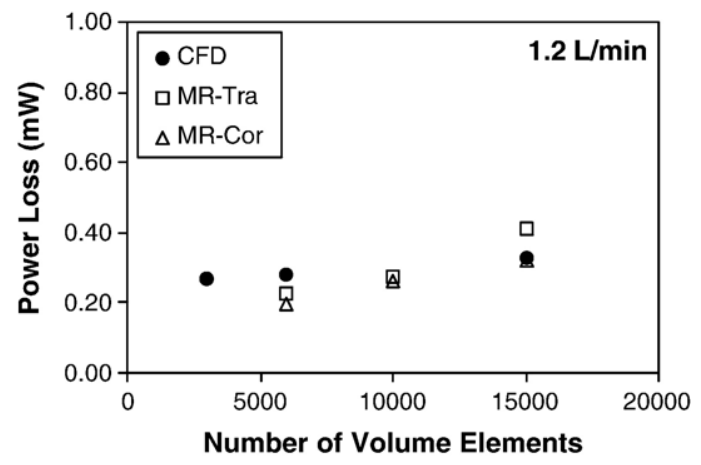

Fig. 7. Rate of VD (power loss) in the tube model calculated from Eq. (1) using the experimental velocity data for both image slice orientations (MR-Tra, transverse; MR-Cor, coronal) and from the computed velocity data. (A) Flow rate of $0.75 \mathrm{~L} / \mathrm{min}$. (B) Flow rate of $1.2 \mathrm{~L} / \mathrm{min}$.

series of meshed models were constructed, with an increasing number of volume elements $(15,000-300,000$ volume elements). The CFD simulations were performed with Fluent under the same flow conditions as those used in the experiments. Water was chosen as the fluid for the simulations. The experimentally measured inlet SVC and IVC velocity profiles with MR PVM were imported into Fluent as the inlet velocity boundary conditions for the simulations, whereas the flow rate split to the RPA and LPA was used as the outlet boundary condition.

\subsection{Data analysis}

Each MR PVM acquisition provided a pair of magnitude and phase images (Fig. 5). A MATLAB code was constructed to process the images and calculate the VD in each case. Each phase image was processed with MATLAB to convert the phase values to velocity values based on their linear relationship. In both geometries and for both slice orientations per geometry, a control volume was selected inside which the calculations of the VD were performed. In the tube case, the volume extended from the top of the arch to $10 \mathrm{~cm}$ away from the arch as shown in Fig. 6A. In the TCPC case, the volume was extended $9 \mathrm{~cm}$ in all four vessels from the center of the model, as shown in Fig. 6B.
In both geometries, the rate of VD (power loss) was calculated from Eq. (1):

$\dot{E}_{\mathrm{loss}}=\mu \sum_{i=1}^{\text {number of voxels }}\left(\Phi_{v} V_{i}\right.$

where $E_{\text {loss }}$ is the rate of energy (power) loss (W), $\mu$ is the dynamic viscosity of the fluid $(\mathrm{kg} / \mathrm{m} \cdot \mathrm{s}), V_{i}$ is the volume of each volume element $\left(\mathrm{m}^{3}\right)$ and $\Phi_{v}$ is the VD function $\left(\mathrm{s}^{-2}\right)$ in each volume element, given Eq. (2) [19]:

$$
\begin{aligned}
\Phi_{v}= & \boldsymbol{z}\left[\left(\frac{\partial v_{x}}{\partial x}\right)^{2}+\left(\frac{\partial v_{y}}{\partial y}\right)^{2}+\left(\frac{\partial v_{z}}{\partial z}\right)^{2}\right]+\left[\frac{\partial v_{y}}{\partial x}\right. \\
& \left.+\frac{\partial v_{x}}{\partial y}\right]^{2}+\left[\frac{\partial v_{z}}{\partial y}+\frac{\partial v_{y}}{\partial z}\right]^{2}+\left[\frac{\partial v_{x}}{\partial z}+\frac{\partial v_{z}}{\partial x}\right]^{2} \\
& -\frac{2}{3}\left[\frac{\partial v_{x}}{\partial x}+\frac{\partial v_{y}}{\partial y}+\frac{\partial v_{z}}{\partial z}\right]^{2}
\end{aligned}
$$

where $v_{x}, v_{y}$ and $v_{z}$ are the three spatial velocity components $(\mathrm{m} / \mathrm{s})$ of the volume element. The velocity gradients in Eq. (2) were calculated as the differences between the velocity values in adjacent volume elements divided by the distance between the centers of these volume elements. This procedure was performed in all three spatial directions and for all three components of the velocity in order to calculate all of the gradients in Eq. (2). These calculations were repeated for all pairs of volume elements in the entire selected volumes of Fig. 6. Then, a summation of all individual dissipation values [Eq. (1)] provided the rate of VD in the entire control volume. Computationally, the VD was similarly calculated in Fluent from the computed velocity data in all volume elements inside the selected volumes of Fig. 6. A user-defined function was used in Fluent to compute the VD combining Eqs. (1) and (2). The VD MR PVM results were compared with the VD CFD

Table 1

VD results for the tube model

\begin{tabular}{lcccc}
\hline & & \multicolumn{3}{l}{$\mathrm{VD}(\mathrm{mW})$} \\
\cline { 4 - 5 } Volume elements* & MR pixel size $\left(\mathrm{mm}^{2}\right)$ & $\mathrm{CFD}$ & MR-Cor & MR-Tra \\
\hline Flow rate $=0.75$ L/min & & & & \\
3,000 & $1 \times 1$ & 0.100 & & \\
6,000 & $0.8 \times 0.8$ & 0.106 & 0.070 & 0.090 \\
10,000 & $0.6 \times 0.6$ & & 0.099 & 0.110 \\
15,000 & & 0.123 & 0.115 & 0.171 \\
& & & & \\
Flow Rate=1.2 L/min & & & & \\
3,000 & $1 \times 1$ & 0.265 & & \\
6,000 & $0.8 \times 0.8$ & 0.279 & 0.194 & 0.229 \\
10,000 & $0.6 \times 0.6$ & & 0.260 & 0.275 \\
15,000 & & 0.0328 & 0.320 & 0.411 \\
\hline
\end{tabular}

* Approximate values. 
results to determine the degree of agreement between them for different spatial resolution settings and flow conditions.

\section{Results}

\subsection{U-shaped tube studies}

Fig. 7 shows the calculated VD in the tube for both flow rates. The three spatial resolution settings from the MR PVM measurements $\left(1 \times 1,0.8 \times 0.8\right.$ and $\left.0.6 \times 0.6 \mathrm{~mm}^{2}\right)$ resulted in approximately $6000,10,000$ and 15,000 volume elements. Therefore, the graphs show CFD results corresponding to only this range in order to make a reasonable comparison. The values are also displayed in Table 1. As seen in Fig. 7, for both flow rates, both the CFD and the MR PVM results show an ascending trend as the spatial resolution (and thus the number of volume elements in the selected volume) increases. Since there were CFD and MR PVM results for approximately 6000 and 15,000 volume elements, it was possible to compare the results quantitatively for these two resolution settings. The average difference between the CFD and the coronal MR PVM results for 6000 and 15,000 volume elements was $25 \%$ and $16 \%$ for 0.75 and $1.2 \mathrm{~L} / \mathrm{min}$, respectively. Similarly, the average difference between the CFD and the transverse MR PVM results was $16 \%$ and $4 \%$ for 0.75 and $1.2 \mathrm{~L} / \mathrm{min}$, respectively. The average difference between the transverse and coronal MR PVM results for all three resolution settings was $23 \%$ and $15 \%$ for 0.75 and $1.2 \mathrm{~L} / \mathrm{min}$, respectively.

\subsection{TCPC phantom studies}

In the TCPC model, the three MR PVM resolution settings resulted in approximately 9000, 15,000 and 23,000 volume elements. Fig. 8 shows the CFD and MR PVM (for both slice orientations) results for a variety of flow splits to the RPA. The MR PVM and the CFD values of VD for the studied range of RPA/LPA flow ratios are also shown in Table 2. The table also shows the average VD values over

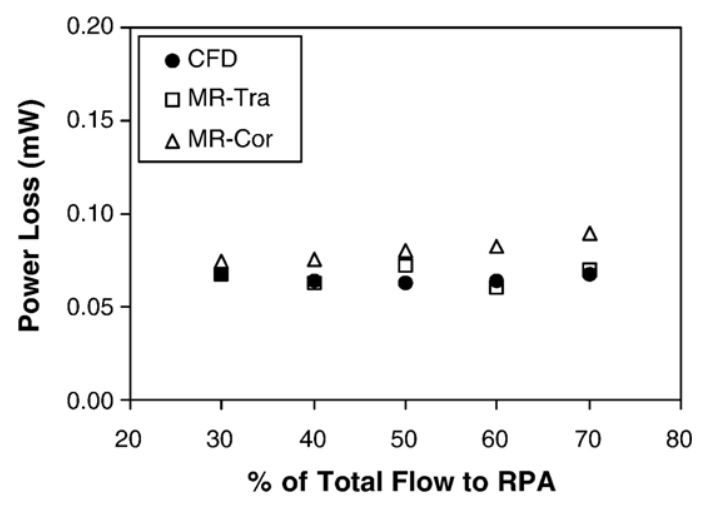

Fig. 8. Rate of VD (power loss) in the TCPC model calculated as the VD from the experimental velocity data for both image slice orientations (MRTra, transverse; MR-Cor, coronal) and from the computed velocity data for different RPA/LPA flow splits. Results correspond to a resolution of $\sim 14,500$ volume elements in both the MR PVM and the CFD cases.
Table 2

VD results for the TCPC model

\begin{tabular}{cllllll}
\hline & \multicolumn{6}{l}{ RPA/LPA flow ratio } \\
\cline { 2 - 7 } & $30: 70$ & $40: 60$ & $50: 50$ & $60: 40$ & $70: 30$ & Average \\
\hline Volume Elements* & CFD VD (mW) & & & \\
15,000 & 0.068 & 0.064 & 0.063 & 0.064 & 0.067 & 0.065 \\
23,000 & 0.075 & 0.071 & 0.07 & 0.071 & 0.075 & 0.072 \\
Volume Elements* & MR-Tra VD (mW) & & & \\
9,000 & 0.052 & 0.053 & 0.05 & 0.052 & 0.058 & 0.053 \\
15,000 & 0.068 & 0.063 & 0.072 & 0.06 & 0.07 & 0.067 \\
23,000 & 0.102 & 0.103 & 0.088 & 0.101 & 0.111 & 0.101 \\
Volume Elements* & MR-Cor VD (mW) & & & \\
9,000 & 0.044 & 0.042 & 0.045 & 0.048 & 0.052 & 0.046 \\
15,000 & 0.074 & 0.076 & 0.08 & 0.083 & 0.089 & 0.080 \\
23,000 & 0.111 & 0.111 & 0.115 & 0.121 & 0.129 & 0.117 \\
\hline
\end{tabular}

* Approximate values.

all flow splits, which are plotted in the graph of Fig. 9. As in the tube case, both the CFD and the MR PVM results show an ascending trend as the spatial resolution increases, although the slope of the MR results is greater than that of the CFD results. Since there were CFD and MR PVM results for approximately 15,000 and 23,000 volume elements, it was possible to compare the results quantitatively for these two resolution settings. The average difference between the CFD and the coronal MR PVM results for 15,000 and 23,000 volume elements was $29 \%$. Similarly, the average difference between the CFD and the transverse MR PVM results was 15\%. The average difference between the coronal and transverse MR PVM results for all three resolution settings was $10 \%$.

\section{Discussion}

The main generator of blood flow in arteries and veins is the pressure from the contraction of the cardiac ventricles. This driving force is necessary to overcome the friction at the wall of the vessels and within the fluid (due to viscosity). The result of this friction is a loss of part of the mechanical energy of the fluid as heat. The traditional

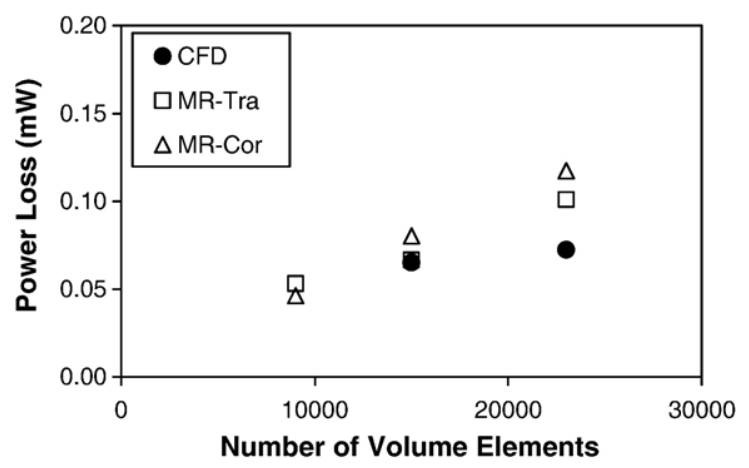

Fig. 9. Rate of VD (power loss) in the TCPC model calculated from Eq. (1) using the experimental velocity data for both image slice orientations (MRTra, transverse; MR-Cor, coronal) and from the computed velocity data. 
approach to determine this energy loss is by applying the mechanical energy balance in a control volume. The energy loss is found as the difference between the inlet and outlet mechanical energy. The application of the mechanical energy balance in the TCPC is shown in Eq. (3):

$$
\begin{aligned}
E_{\text {loss }}= & {\left[Q_{\mathrm{SVC}} P_{\mathrm{SVC}}+Q_{\mathrm{IVC}} P_{\mathrm{IVC}}-Q_{\mathrm{RPA}} P_{\mathrm{RPA}}-Q_{\mathrm{LPA}} P_{\mathrm{LPA}}\right] } \\
& +\left[q_{\mathrm{SVC}}^{1 / 2} \rho\left(v_{\mathrm{SVC}}\right)^{2}+Q_{\mathrm{IVC}}^{1 / 2} \rho\left(v_{\mathrm{IVC}}\right)^{2}-Q_{\mathrm{RPA}}^{1 / 2} \rho\left(v_{\mathrm{RPA}}\right)^{2}\right. \\
& \left.-Q_{\mathrm{LPA}}^{1 / 2} \rho\left(v_{\mathrm{LPA}}\right)^{2}\right]
\end{aligned}
$$

where $P_{i}$ is the static pressure $(\mathrm{Pa})$ in each vessel, $\rho$ is the fluid density $\left(\mathrm{kg} / \mathrm{m}^{3}\right), Q_{i}$ is the volumetric flow rate in each vessel $\left(\mathrm{m}^{3} / \mathrm{s}\right)$ and $v_{i}$ is the cross-sectional average velocity in each vessel $(\mathrm{m} / \mathrm{s})$ determined from the flow rate and the vessel area. As can be seen from the equation, in order to calculate the power loss, the pressure has to be measured in the SVC, IVC, LPA and RPA. This is clinically problematic because these measurements can only be performed invasively with catheters placed in all these vessels in a precise manner. Therefore, another method is necessary to determine the energy loss in patients.

In fluid mechanics, this irreversible energy loss, being due to viscous effects, is called viscous dissipation and it can be calculated by applying Eq. (1) and Eq. (2). Computationally, it has recently been shown $[20,21]$ that the energy loss calculated with Eq. (1) agrees with the energy loss calculated with Eq. (3). The present study is a first attempt to examine the applicability of the VD method using a clinical technique. We focused our analysis on comparisons between MR PVM results with CFD results (which are treated as the reference) of the VD for similar spatial resolutions, in order to determine the feasibility of the new method clinically.

The fact that both the MR PVM and the CFD results showed generally the same trend and close agreement is very promising for the potential of the VD method. Nevertheless, the ascending tendency of the VD results as the volume elements decreased in size suggests that the spatial resolution is a key element for the reliability of the method clinically. To better understand the effect of the resolution, we performed a series of CFD simulations increasing the number of volume elements to such levels so that grid independency could be achieved. Fig. 10 shows these simulation results for the VD for both models. In the tube case, the power loss result increases significantly as the resolution increases and it tends to reach a plateau for more than 40,000 volume elements. In the TCPC case, again the power loss results increase with the resolution and a plateau is established for more than 50,000 volume elements. The power loss results calculated using Eq. (1) (VD) agrees very closely with the power loss result calculated using the traditional mechanical energy balance equation [Eq. (3)], with a difference of less than $5 \%$ for the tube model and approximately $18 \%$ for the TCPC model.
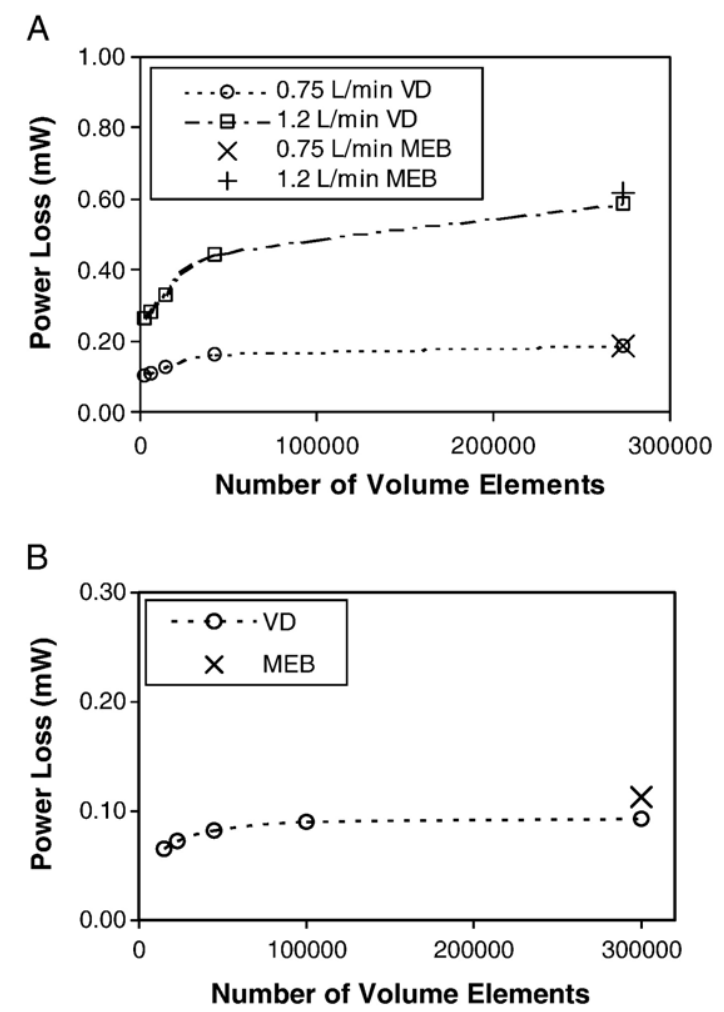

Fig. 10. CFD-computed rate of VD as a function of grid density. (A) Ushaped tube, (B) TCPC. The single "+" point and the single " $\times$ " point correspond to the power loss calculated using the mechanical energy balance (MEB) equation [Eq. (3)]. As seen in the figure, the VD and the MEB methods provided the same power loss results for the highest resolution grid studied.

This analysis shows that, indeed, the VD method as applied using MR PVM is a reliable approach for the assessment of the fluid mechanical energy losses in the two models of the study since there is good agreement with CFD results of similar spatial resolution. Nevertheless, an important finding is that the MR PVM results correspond not to the plateau but rather to the ascending parts of the curves of Fig. 10A and $\mathrm{B}$ under the spatial resolution settings used in this study (volume element sizes of $5 \times 1 \times 1$, $5 \times 0.8 \times 0.8$ and $\left.5 \times 0.6 \times 0.6 \mathrm{~mm}^{3}\right)$. A quantitative analysis shows that the differences of the MR PVM results from the plateau values are in the range of $30-40 \%$. Although this is actually not a big difference considering the nature of the VD method, the study shows that the MR PVM results of the VD can reach the true energy loss values by achieving image acquisitions of higher spatial resolution.

Achieving MR image acquisitions with higher resolutions than those of this study is currently problematic. Although there is the potential of increasing the matrix size and reducing the FOV further than the settings of the study, the signal-to-noise ratio will be too low to assure reliable image data analysis. In this study, a volume element size of $5 \times 0.6 \times 0.6 \mathrm{~mm}^{3}$ was the smallest possible to allow an adequate construction of the CFD models. However, with future advancement in MR acquisition technology, 
achieving higher quality images with higher resolutions is possible.

Another important finding of the study was the similarities between the MR PVM results with the coronal and the transverse slice orientation. This is very important considering the large difference in the number of slices necessary to image the region of interest in both models (20 transverse vs. 3 coronal in the tube; 36 transverse vs. 3 coronal in the TCPC). Currently, the scan time for ECGgated acquisitions of three slices with all velocity components is $3-10 \mathrm{~min}$ depending on the degree of $k$-space segmentation $[37,38]$; the scan time would be 15-30 min for 20 slices and more than 35 min for 36 slices, making the clinical implementation of the method impractical and unappealing.

In conclusion, this is the first systematic study of the feasibility of the VD method via a clinical protocol. The VD method can provide a quantification of the energy losses in surgical vascular configurations such as the TCPC without the need for invasive pressure measurements. The results of this study show that MR PVM has great potential as a clinical technique for a noninvasive quantification of the VD in the cardiovascular system. Increasing of the spatial resolution of the three-directional velocity acquisitions increases the accuracy of the calculation of the power loss.

\section{Acknowlegments}

Support by Cleveland State University is greatly appreciated.

\section{References}

[1] de Leval MR, Kilner P, Gewillig M, Bull C. Total cavopulmonary connection: a logical alternative to atriopulmonary connection for complex Fontan operations. J Thorac Cardiovasc Surg 1988;96: 682-95.

[2] Pearl JM, Laks H, Stein DG, Drinkwater DC, George BL, Williams RG. Total cardiopulmonary anastomosis versus conventional modified Fontan procedure. Ann Thorac Surg 1991;52:189-96

[3] Podzolkov VP, Zaets SB, Chiaureli MR, Alekyan BG, Zotova LM, Chernikh IG. Comparative assessment of Fontan operation in modifications of atriopulmonary and total cavopulmonary anastomoses. Eur J Cardiothorac Surg 1997;11:458-65.

[4] Low HT, Chew YT, Lee CN. Flow studies on atriopulmonary and cavopulmonary connections of the Fontan operations for congenital heart defects. J Biomed Eng 1993;15:303-7.

[5] Lardo AC, Webber SA, Iyengar A, delNido PJ, Friehs I, Cape EG. Bidirectional superior cavopulmonary anastomosis improves mechanical efficiency in dilated atriopulmonary connections. J Thorac Cardiovasc Surg 1999;118:681-91.

[6] Dubini G, de Leval MR, Pietrabissa R, Montevecchi FM, Fumero R. A numerical fluid mechanical study of repaired congenital heart defects: application to the total cavopulmonary connection. J Biomech 1996;29:111-21.

[7] de Leval MR, Dubini G, Migliavacca F, Jalali H, Camporini G, Redington A, et al. Use of computational fluid dynamics in the design of surgical procedures: application to the study of competitive flows in cavopulmonary connections. J Thorac Cardiovasc Surg 1996;111: $502-13$.
[8] Walker PG, Howe TT, Davies RL, Fisher J, Watterson KG. Distribution of hepatic venous blood in the total cavo-pulmonary connection: an in vitro study. Eur J Cardiothorac Surg 2000;17: $658-65$.

[9] Migliavacca F, de Leval MR, Dubini G, Pietrabissa R, Fumero R. Computational fluid dynamic simulations of cavopulmonary connections with an extracardiac lateral conduit. Med Eng Phys 1999;21: 187-93.

[10] Migliavacca F, Kilner PJ, Pennati G, Dubini G, Pietrabissa R, Fumero $\mathrm{R}$, et al. Computational fluid dynamics and magnetic resonance analysis of flow distribution between the lungs after total cavopulmonary connection. IEEE Trans Biomed Eng 1999;46:393-9.

[11] Sharma S, Goudy S, Walker P, Panchal S, Ensley A, Kanter K, et al. In vitro flow experiments for determination of optimal geometry of the total cavopulmonary connection for surgical repair of children with functional single ventricle. J Am Coll Cardiol 1996;27:1264-9.

[12] Lardo AC, Webber SA, Friehs I, delNido PJ, Cape EG. Fluid dynamic comparison of intra-atrial and extracardiac total cavopulmonary connections. J Thorac Cardiovasc Surg 1999;117:697-704.

[13] Ensley A, Lynch P, Chatzimavroudis GP, Lucas C, Sharma S, Yoganathan AP. Toward designing the optimal total cavopulmonary connection: an in vitro study. Ann Thorac Surg 1999;68:1384-90.

[14] Ensley AE, Ramuzat A, Healy TM, Chatzimavroudis GP, Lucas C, Sharma S, et al. Fluid mechanic assessment of the total cavopulmonary connection using magnetic resonance phase velocity mapping and digital particle image velocimetry. Ann Biomed Eng 2000;28: $1172-83$.

[15] Sharma S, Ensley AE, Hopkins K, Chatzimavroudis GP, Healy TM, Tam VKH, et al. In vivo flow dynamics of the total cavopulmonary connection from three-dimensional multislice magnetic resonance imaging. Ann Thorac Surg 2001;71:889-98.

[16] Khunatorn Y, Shandas R, DeGroff C, Mahalingam S. Comparison of in vitro velocity measurements in a scaled total cavopulmonary connection with computational predictions. Ann Biomed Eng 2003; 31:810-22.

[17] Hsia T-Y, Migliavacca F, Pittaccio S, Radaelli A, Dubuni G, Pennati $\mathrm{G}$, et al. Computational fluid dynamic study of flow optimization in realistic models of the total cavopulmonary connections. J Surg Res 2004;116:305-13.

[18] de Zelicourt DA, Pekkan K, Wills L, Kanter K, Forbess J, Sharma S, et al. In vitro flow analysis of a patient-specific intraatrial total cavopulmonary connection. Ann Thorac Surg 2005;79:2094-102.

[19] Bird RB, Stewart WE, Lightfoot EN. Transport phenomena. New York: Wiley; 1960.

[20] Healy TM, Lucas C, Yoganathan AP. Noninvasive fluid dynamic power loss assessments for total cavopulmonary connections using the viscous dissipation function: a feasibility study. J Biomech Eng 2001; 123:317-24.

[21] Liu YT, Pekkan K, Jones SC, Yoganathan AP. The effects of different mesh generation methods on computational fluid dynamic analysis and power loss assessment in total cavopulmonary connection. J Biomech Eng 2004;126:594-603.

[22] Moran PR. A flow velocity zeugmatographic interlace for NMR imaging in humans. Magn Reson Imaging 1982;1:197-203.

[23] Frayne R, Steinman DA, Ethier CR, Rutt BK. Accuracy of MR phase contrast velocity measurements for unsteady flow. J Magn Reson Imaging 1995;4:428-31.

[24] McCauley TR, Pena CS, Holland CK, Price TB, Gore JC. Validation of volume flow measurements with cine phase contrast MR imaging for peripheral arterial waveforms. J Magn Reson Imaging 1995;5: $663-8$.

[25] Klipstein RH, Firmin DN, Underwood SR, Rees RSO, Longmore DB. Blood flow patterns in the human aorta studied by magnetic resonance. Br Heart J 1987;58:316-23.

[26] Mohiaddin RH, Wann SL, Underwood R, Firmin DN, Rees S, Longmore DB. Vena caval flow: assessment with cine MR velocity mapping. Radiology 1990;177:537-41. 
[27] Meier D, Maier S, Bosiger P. Quantitative flow measurements on phantoms and on blood vessels with MR. Magn Reson Med 1988;8: $25-34$.

[28] Bendel P, Buonocore E, Bockisch A, Besozzi MC. Blood flow in the carotid arteries: quantification by using phase-sensitive MR imaging. Am J Roentgen 1989;152:1307-10.

[29] Pelc LR, Pelc NJ, Rayhill SC, et al. Arterial and venous blood flow: noninvasive quantitation with MR imaging. Radiology 1992;185: $809-12$.

[30] Kilner PJ, Yang GZ, Mohiaddin RH, Firmin DN, Longmore DB. Helical and retrograde secondary flow patterns in the aortic arch studied by three-directional magnetic resonance velocity mapping. Circulation 1993;88:2235-47.

[31] Bogren HG, Buonocore MH. Blood flow measurements in the aorta and major arteries with MR velocity mapping. J Magn Reson Imaging 1994:4:119-30.

[32] Chatzimavroudis GP, Oshinski JN, Franch RH, Walker PG, Yoganathan AP, Pettigrew RI. Evaluation of the precision of magnetic resonance phase velocity mapping for blood flow measurements. J Cardiovasc Magn Res 2001;3:11-9.

[33] Zhang H, Halliburton SS, White RD, Chatzimavroudis GP. Fast measurements of flow through mitral regurgitant orifices with magnetic resonance phase velocity mapping. Ann Biomed Eng 2004;32:1618-27.

[34] Zhang H, Halliburton SS, Venkatachari AK, Setser RM, White RD, Chatzimavroudis GP. Reliable in-plane velocity measurements with magnetic resonance velocity imaging. Flow Measurement and Instrumentation 2006;17:75-80.

[35] Be'eri E, Maier SE, Landzberg MJ, Chung T, Geva T. In vivo evaluation of Fontan pathway flow dynamics by multidimensional phase-velocity magnetic resonance imaging. Circulation 1998;98: 2873-82.

[36] Morgan VL, Graham TP, Roselli RJ, Lorenz CH. Alterations in pulmonary artery flow patterns and shear stress determined with threedimensional phase contrast magnetic resonance imaging in Fontan patients. J Thorac Cardiovasc Surg 1998;116:294-304.

[37] Poutanen V-P, Kivisaari R, Häkkinen A-M, Savolainen S, Hekali P, Standertskjöld-Nordenstam C-G. Multiphase segmented $k$-space velocity mapping in pulsatile flow waveforms. Magn Reson Imaging 1998; 16:261-9.

[38] Zhang H, Halliburton SS, Moore JR, Simonetti OP, Schvartzman PR, White $\mathrm{RD}$, et al. Ultrafast flow quantification with segmented $k$-space magnetic resonance phase velocity mapping. Ann Biomed Eng 2002; $30: 120-8$ 